\title{
sciendo
}

\section{Agent Causation Is Not Prior to Event Causation}

\begin{abstract}
Soo Lam Wong
Singapore University of Social Sciences

DOI: $10.2478 /$ disp-2021-0008

BIBLID [0873-626X (2021) 61; pp.143-58]

Abstract

My aim in this paper is to argue against the claim that agent causation is more fundamental than event causation. To accomplish this aim, I shall first briefly discuss the motivation behind agent causation. Second, I shall highlight the differences between agent causation and event causation. Third, I shall begin briefly with the weaker claim held by Timothy O'Connor and Randolph Clarke that there is no good reason to believe that event causation is more fundamental than agent causation. Fourth, I shall discuss the stronger claim held by E. J. Lowe that agent causation is more fundamental than event causation, and raise objections against the various arguments Lowe advances for the stronger claim. To the extent that my objections against Lowe's stronger claim succeed, they raise questions for O'Connor's and Clarke's weaker claim.
\end{abstract}

\section{Keywords}

Agent, Substance, Event, Causation, Free Will.

\section{Introduction}

My aim in this paper is to argue against the claim that agent causation is more fundamental than event causation. To accomplish this aim, I shall first briefly discuss the motivation behind agent causation. Second, I shall highlight the differences between agent causation and event causation. Third, I shall begin briefly with the weaker claim held by Timothy O'Connor and Randolph Clarke that there is no good reason to believe that event causation is more fundamental than agent causation. Fourth, I shall discuss the stronger claim held by E. J. Lowe that agent causation is more fundamental than event causation, and raise objections against the various arguments Lowe advances for the stronger claim. To the extent that my objec- 
tions against Lowe's stronger claim succeed, they raise questions for O'Connor's and Clarke's weaker claim.

\section{The motivation behind agent causation}

The dilemma of free will is that if our choices are caused deterministically, then they are not free; and if they are not caused deterministically, then they are not free either, because then they happen by chance and are not up to us. Agent causation is attractive because it resolves this dilemma by asserting that choices are agent-caused or agent-determined and hence they are up to the agent (as a substance) despite external (physical states), internal (mental states) causes or determinants and chance factors. Moreover, this feature of agent causation has implications for moral responsibility. On the eventcausal account, both determinism and indeterminism are incompatible with the freedom of choice because our choices are not up to us. In other words, both determinism and indeterminism are incompatible with the attribution of ultimate moral responsibility. Attribution of ultimate moral responsibility requires absolute freedom of choice, which in turn requires that our choices are up to us. So, by postulating that our choices are up to us, agent causation can secure absolute freedom of choice, which in turn secures the attribution of ultimate moral responsibility. Put another way, only agent causation is compatible with the absolute freedom of choice as well as ultimate moral responsibility.

\section{Event causation versus agent causation}

One influential account of events by Jaegwon Kim (1975) defines an event as an object (or a certain group of objects) exemplifying a particular property (or properties) at a certain time. In event causation, to say that one event-causes another event is to say that an object $\mathrm{x}$ exemplifying a property $\mathrm{p}$ at time $\mathrm{t}_{0}$ causes an object y exemplifying property $\mathrm{q}$ at time $\mathrm{t}_{1}$. In short, event $\mathrm{x}$ causes event $\mathrm{y}$ means event $(\mathrm{x}$, $\mathrm{p}, \mathrm{t}_{0}$ ) causes event $\left(\mathrm{y}, \mathrm{q}, \mathrm{t}_{1}\right)$. Kim's account can be refined to capture extensions in time, where $t_{0}$ or $t_{1}$ can be taken to refer to a certain duration of time instead of a certain time. A similar account by Rich- 
ard Taylor (1966) states that an event can be defined as a change (or persistence) in the state of a substance at a certain time. Both causes and effects are either changes in the states or the persistence of states of substances at particular times. According to the event-causal account, causation is a direct relationship between changes of states or persistence of states, and only an indirect relationship between the substances themselves to which those states belong. However, Taylor's account can be refined to include the claim that substances provide the necessary material and structural conditions of bearing certain states. Building on Kim's and Taylor's accounts, the eventcausal account I favour takes causation as a direct relationship between the objects exemplifying certain properties (or substances in certain states) at certain times, as illustrated below:

$\begin{array}{lll}\ldots \text { Event a } & \text { Event } \mathrm{b} \rightarrow & \text { Event } \mathrm{c} \ldots \\ \text { Object } \mathrm{x} \text { exemplifying } & \text { Object y exemplifying } & \text { Object } \mathrm{z} \text { exemplifying } \\ \text { Property P at } & \text { Property Q at } & \text { Property } \mathrm{R} \text { at } \\ \text { Time } \mathrm{t}_{0} & \text { Time }_{1} & \text { Time } \mathrm{t}_{2}\end{array}$

It is generally accepted that only events can be the relatas of causation. According to the standard event-causal account, objects have causal powers in virtue of their properties. When an object $\mathrm{x}$ exemplifies property $\mathrm{P}$ in some circumstance $\mathrm{c}$ at some earlier time, $P$ causes (either deterministically or indeterministically) a certain effect at some later time. 'Cause' means 'necessitate' (if deterministic) or 'incline' (if indeterministic). Hence, P necessitates or inclines $\mathrm{x}$ to cause Q in y, given c. Sydney Shoemaker calls event causation "simple functions from circumstances to effect" (Shoemaker 1984: 212). Shoemaker's account takes properties but not objects as the bearers of causal powers. However, if we take objects as the necessary material and structural conditions of exemplifying certain properties, then we can take the object, together with the properties it exemplifies, under certain circumstances, as an entity that has causal powers. The event-causal account I favour attributes causal powers to objects exemplifying properties under certain circumstances as a whole rather than objects, properties, or circumstances 
alone. Put simply, Px necessitates or inclines Qy, given c. In cases where an agent causes an action, both the cause of the action and the action itself are events involving an agent. It consists of an agent (or a subject), exemplifying certain properties (or be in certain states) at some earlier time, causing her to exemplify certain properties (or be in certain states) at some later time, under certain circumstances.

For Timothy O'Connor (1995), proponents of agent causation are committed to the causal relation between an agent and an event, where an agent is a substance that directly and purposively initiates, originates, produces, or brings about an event. It is therefore a direct relationship between a substance and an event, as illustrated below:

$\begin{array}{lll}\text { Agent } \mathrm{x} \rightarrow & \text { Event a } & \text { Event } \mathrm{b} \ldots \\ & \text { Object } \mathrm{x} \text { exemplifying } & \text { Object } \mathrm{y} \text { exemplifying } \\ & \text { Property Pat } & \text { Property } \mathrm{Q} \text { at } \\ & {\text { Time } \mathrm{t}_{0}} & \text { Time }_{1}\end{array}$

This direct relationship between a substance and an event can be analysed further. When an agent exercises her unique causal powers (what O'Connor calls 'volitional-enabling active powers' or 'choiceenabling active powers'), she can be said to exemplify a certain property at a certain time that brings about events, as illustrated below:

\begin{tabular}{|c|c|c|}
\hline Agent $x$ & Event b & Event c... \\
\hline Exercises VE ${ }^{1}$ & Object y exemplifying & Object $\mathrm{z}$ exemplifying \\
\hline Active Powers at & Property P at & Property Q at \\
\hline Time $t_{0}$ & Time $t_{1}$ & Time $t_{2}$ \\
\hline
\end{tabular}

As O'Connor does not make any claim concerning the temporal conditions of agent-causes, I shall assume that on the agent-causal account, agents as substance can exercise volitional-enabling active powers whenever she wants it, which I believe is consistent with O'Connor's view. When an agent $\mathrm{x}$ exemplifies property $\mathrm{P}$ (voli-

\footnotetext{
${ }^{1}$ Volitional Enabling.
} 
tional-enabling active powers) at some earlier time, P neither necessitates nor makes probable, but merely makes possible, a certain effect at some later time. Hence, x's exemplification of $\mathrm{P}$ makes it possible for it to cause y directly. In contrast with Taylor's and Shoemaker's views, it is $\mathrm{x}$ (substance) alone, and not $\mathrm{P}$ (properties or states), that causes y (action). In cases of an agent causing an action, the cause of action is solely the agent (substance) whereas the action itself is an event involving an agent. According to O'Connor, insofar as an effect is directly and purposively caused by an agent, agent causation cannot be "simple functions from circumstances to effects" (O’Connor 1995: 177).

The key difference between event causation and agent causation lies in the presence or absence of antecedent causal conditions. On the event-causal account, all events have antecedent causal conditions, whether deterministic or indeterministic. There are antecedent causal conditions for objects to exemplify certain properties at earlier times, and certain properties exemplified by objects necessitate or make probable certain events at later times. On the agentcausal account, there are no antecedent causal conditions for when and why agents exercise their volitional enabling causal powers, and the volitional enabling causal powers exemplified by agents merely make possible, but neither necessitate nor make probable events at later times. Since it is up to the agents whether or not to exercise their unique causal powers, we can refer to the agents, and not their unique properties or causal powers, as the source of direct and purposive causes of events. In short, an agent-cause is an uncaused cause whereas an event-cause is a caused cause.

\section{Arguments for prioritising agent causation over event causation}

Responding to C.D. Broad's objection to agent causation in a later paper, O'Connor questions the claim that events are ontologically prior to substances, and that substances existing at a time depends metaphysically upon events (that involve them) existing at a time. He suggests a more symmetrical alternative where substances and events are not ontologically prior to each other, or where substances 
and events are metaphysically dependent upon each other, and expresses it as follows:

[N]ecessarily, an object $\mathrm{O}$ at time $\mathrm{t}$ exists only if there is some event $\mathrm{E}$ that involves it occurs at time $t$, and for any event $E$ that occurs at time $t$ that involves object $\mathrm{O}$, necessarily, event $\mathrm{E}$ occurs only if object $\mathrm{O}$ exists at time t. (O'Connor 2009: 377)

Similarly, Randolph Clarke argues that causal relata are concrete particulars, including substances and events. If events can be causes but not substances, then there must be some reason for this difference. It is inadequate to claim that the implausibility, if not impossibility of, substance as causes is self-evident. As there are no adequate accounts of this difference so far, causation by substances remains a possibility. (Clarke 2009: 347) E.J. Lowe (2008) takes a step further. Instead of arguing for a more symmetrical treatment of substance or agent causation and event causation like O'Connor and Clarke, he argues for the prioritisation of substance or agent causation over event causation. Lowe defines an agent as a persisting object or an individual substance that possesses various properties, including certain causal powers and liabilities. A causal power is a power to cause some object to act in a certain way, for example, a power to cause sugar to dissolve. And a causal liability is a power to be caused by some object to act in a certain way, for example, a power to be caused to dissolve in water.

In arguing for the conceptual priority of agent causation, Lowe observes that only a creature capable of intentional action can acquire knowledge of causal relations between events from experience. Such a creature must not only be an agent, but must also be aware of being an agent in order to possess the concept of agent causation. As causal agents, we are aware of our ability to intervene in and manipulate the course of nature, and we are able to test causal hypotheses experimentally and thereby distinguish (not infallibly) between causal and non-causal events. An important component of this ability to intervene in the course of nature is our capacity to move ourselves at will in accordance with our desires (within limits) rather than being moved entirely by external factors. In contrast, a purely passive creature, however acute its powers of observation, would be incapable of discriminating empirically between causal and non-causal sequences 
of event, and hence it seems reasonable to conclude that it has no concept of event causation. As the concept of agent causation cannot be derived from the concept of event causation because possession of the former concept is necessary for the possession of the latter concept, it cannot be the case that we first learn to apply the concept of event causation to observable events and then learn to conceive of ourselves as agents. (Lowe 2008: 134-5) Moreover, Lowe claims that we use the language of agent causation rather than the language of event causation to describe our action and that "we resort to the latter... primarily when we are at least partially ignorant about the causal agents that are at work". In anticipating an objection, he acknowledges that event-causal theorists accord ontological priority to event causation because events seem more epistemically accessible than substances or agents. However, he regards this event-causal objection as "the legacy of an empiricist epistemology which distrusts all talk of causal machinery at work in the real world behind the shifting scenes of appearance" (Lowe 2008: 138-9).

In arguing for the ontological priority of agent causation, Lowe claims that events, of themselves, possess no causal powers and liabilities. Only persisting objects or individual substances do. It is such entities that we describe as being magnetic, corrosive, inflammable, soluble, and so forth. Objects and substances manifest or display their causal powers and liabilities by acting on things, or being acted upon by things, in various appropriate ways, by attracting, corroding, burning, dissolving, and so forth. Agent causation should be conceived of as a species of substance causation. In describing such activities, we use the language of agent causation rather than the language of event causation. We resort to the latter when we are at least partially ignorant about the causal agents that are at work. (Lowe 2008: 138) On Lowe's account, what it is for water to dissolve salt is precisely for water to cause salt to dissolve. For $\mathrm{x}$ to dissolve $\mathrm{y}$ is for $\mathrm{x}$ to cause $\mathrm{y}$ to dissolve, just as for $\mathrm{x}$ to move $\mathrm{y}$ is for $\mathrm{x}$ to cause y to move. (Lowe 2008: 144-5) Dissolving and moving are species of causation and the entities that engage in these species of causation are individual substances or persisting objects of various kinds. It is plausible to say that whenever a substance causes an event, it does so by acting in a certain manner and that its acting in such a manner constitutes an event. So, instead of the reducibility of substance 
causation to event causation, it seems that the reverse is true.

In arguing for the necessity of postulating uncaused agent-causes, Lowe claims that the free will problem is intractable because the contemporary free will debate is conducted in terms of a mistaken approach to causality in general, which assumes that all causation is fundamentally event causation. (Lowe 2008: 141) By insisting that an event must either have or lack a further event-cause, we are faced with a dilemma. For if our choices are caused, we lack genuine freedom and responsibility. And if our choices are uncaused, they seem to be mere chance happenings, and we lack genuine freedom and responsibility too. As Lowe says:

A human agent must then be seen as no 'freer'...than the boulder which rolls into the tree, its rolling being caused by the action of some other object upon it, which action is in turn caused by yet earlier events... Acknowledging that there is room for a certain amount of probabilistic causation between events provides no escape from this conclusion, since a boulder's behaviour would be no 'freer' on that account than it would be in a perfectly deterministic universe. (Lowe 2008: 128)

Lowe argues that this dilemma can be resolved by holding that an agent-cause is itself uncaused without implying that an agent-cause is a mere chance happening: for an agent-cause is not a happening, an event, and is therefore not the sort of thing to have an event as a cause.

\section{Arguments against prioritising agent causation over event causation}

On Lowe's argument for the conceptual priority of agent causation, I agree with his plausible premise that we must be aware of ourselves as active causal agents before we can understand event causation and this involves having the capacity to move ourselves at will in accordance with our internal factors rather than being moved entirely by external factors. However, I disagree that this premise leads to the conclusion that acquiring the concept of agent causation is a prerequisite of acquiring the concept of event causation, or that agent causation is conceptually prior to event causation. The analysis in the water and salt example discussed above can be extended to human 
agents. Conceiving ourselves as active causal agents need not be conceiving ourselves as basic, primitive, simple or un-analysable agentcauses; it can also be conceiving ourselves as event-causes - as agents having internal states such as character and personality, desires and beliefs, preferences and values, and sensitivity and responsiveness to external circumstances and situations, at certain times. As Lowe notes, epistemic accessibility does favour the event-causal conception of ourselves as configurations of organic molecules possessing certain psychological properties and intentional states such as character and personality, desires and beliefs, preferences and values, and sensitivity and responsiveness to external circumstances and situations, at certain times, over the agent-causal conception of ourselves as basic, primitive, simple, or un-analysable entities that can bear properties or be in certain states. In contrast, given the agent-causal conception of substances or agent as basic, primitive, simple, or unanalysable entities that can bear properties or be in certain states, how can we gain epistemic access to the 'causal machinery at work in the real world behind the shifting scenes of appearance'? On the more epistemically accessible event-causal view, what we acquire is the concept of event causation involving human agents rather than agent causation. And it draws the alternative conclusion that event causation involving human agents is a pre-requisite of (or is conceptually prior to) event causation involving non-human agents. Acquisition of agent causation is then not a necessary pre-requisite of (or is not conceptually prior to) event causation.

Lowe's premise that we use the language of event causation when we are at least partially ignorant about the causal agents at work puts the cart before the horse. Event-causal theorists can object that the agent-causal descriptions 'causal agents at work' and 'agents acting in certain manners' are a shorthand for the event-causal descriptions 'objects having certain properties' and 'subjects being in certain states'. They can claim that all the four phrases are different descriptions of a single event, with the agent-causal pair being less detailed (coarse-grained) and the event-causal pair being more detailed (finegrained), and argue that it is more plausible to suppose that we use the less detailed agent-causal shorthand when we are at least partially ignorant about the more detailed event-causal longhand. At length, they can argue that it is more plausible to suppose that we describe 
substances or agents as basic, primitive, simple, or un-analysable entities 'at work' or 'acting in certain manners' when we are partially ignorant about objects and subjects structured in certain ways having certain properties, being in certain states, and thereby possessing certain causal powers and liabilities at certain times. Applying this detailed event-causal analysis to Lowe's water and salt example, water can be analysed as hydrogen and oxygen atoms structured in certain ways having certain properties and states such as liquidity and solvency, and hence possessing the causal power to dissolve salt, which can be analysed as sodium and chlorine atoms structured in certain ways having certain properties or states such as solidity and solubility, and hence possessing the causal liability to dissolve in water. And the cursory agent causal analysis of water and salt as basic, primitive, simple, or un-analysable entities that can bear certain properties or be in certain states is used when we are at least partially ignorant of the deeper processes of solvency and solubility and the inner workings of water and salt. To say 'for water to dissolve salt is for water to cause salt to dissolve', in the coarse-grained language of agent causation, then is just an abbreviated way of talking about the processes of solvency and solubility involving water and salt in terms of their constituents, structures, properties, and states, in the fine-grained language of event causation. Mere use of abbreviated language that exclude relevant details does nothing to show that substances are basic, primitive, simple, or un-analysable entities, or that such entities in and of themselves can be causes; it just shows that the relevant details are ignored. On the contrary, the converse of Lowe's premise that we use the language of agent causation when we are at least partially ignorant about the deeper processes of events involving agents, and the inner workings of agents, properties, and states, supports the converse of Lowe's conclusion that event causation is conceptually prior to agent causation, thereby putting the horse back in front of the cart.

On Lowe's argument for the ontological priority of agent causation, I agree with his plausible premise that substances or agents possess causal powers and liabilities. However, I disagree that substances or agents simpliciter possess causal powers and liabilities. According to the standard event-causal account, it is not the substances or agents of themselves, but something about the substances or agents 
(their material and structural conditions), that enable them to possess causal powers and liabilities. It is iron's atomic constitution, along with its crystalline structure and electronic configuration, and not iron substance of itself, that makes it magnetic. Similarly, it is oxygen's atomic constitution in the presence of water and electrolytic environment, and not water substance of itself, that make it corrosive. Hence, the event-causal account has more explanatory power: it can explain why, when, and how objects manifest or display their causal powers and liabilities, by gaining or losing certain properties, or by changing to or persisting in certain states at a certain time. In contrast, other than by stipulation, the agent-causal account can hardly explain why, when, and how substances or agents simpliciter can bear certain properties or be in certain states, manifest or display their causal powers and liabilities by acting on things, or being acted upon by things. That is, substances or agents simpliciter are treated as unexplained explanans - they are postulated to explain the effects that they cause and yet, they themselves are left unexplained. C.D. Broad (1952) and Carl Ginet (1997, 1990) developed variants of this criticism. Without appealing to the material and structural conditions (hydrogen and oxygen atoms structured in certain ways) of substances or agents, substances or agents simpliciter (water as basic, primitive, simple, or un-analysable substances) cannot account for how they bear certain properties (liquidity and solvency) or be in certain states. Without appealing to the presence or absence of certain properties (liquidity and solvency) or states (solid, liquid, gaseous), or circumstances (temperature and pressure), at certain times, substances or agents simpliciter cannot account for how substances or agents come to possess causal powers and liabilities, and how they act on things or are acted upon by things. Agent causalists may object that even if the event-causal account has more explanatory power than the agent-causal account (an epistemological claim), it does not show that event causation is hence ontologically prior to agent causation (an ontological claim). In response, event causalists can claim that as substances or agents simpliciter cannot be said to possess causal powers and liabilities without their material and structural conditions, it can hardly be said that substance or agent causation is ontologically prior to event causation.

Despite the conceptual difficulties raised by the agent causal 
account, agent causal theorists may nonetheless insist that agent causation remains the only satisfactory solution to the free will problem. This is perhaps the strongest justification for the agent causal account. As discussed above, the motivation behind postulating uncaused agent-causes, in the case of human agents, is the worry that the causal relevance of human agents seems to be lost in the eventcausal account, where causal relata are the properties and states of the agent rather than the agent as a substance. This leads to the further worry that the loss of causal relevance of human agents implies the loss of absolute free will and hence ultimate moral responsibility. However, event-causal theorists can still affirm the causal relevance of human agents and still question the necessity of positing absolute free will and ultimate moral responsibility. The fact that something is caused does not mean that it cannot also cause something else, or in Lowe's terms, the fact that something possesses a causal liability does not mean that it cannot also possess a causal power. On the event-causal account, an object or subject, along with its properties or states, is a necessary constituent of an event-cause (and hence is causally relevant), by being the material and structural conditions of the properties and states it/she has. A property or state cannot exist without an object or subject that possess it, and an object or subject must have at least one property or be in at least one state to manifest or display its/her causal powers and liabilities. In the water and salt example, water has the power of liquidity and solvency by being hydrogen and oxygen atoms structured in certain ways having certain chemical properties. Similarly, in the human agent example, the human agent has the power to act in certain ways by being organic molecules structured in certain ways having certain biological and psychological properties. Agent-causal theorists may insist that the worry remains because an event-cause involving a human agent is something happening to or something occurring in the human agent, and hence the event-cause can never be an action or a doing. In other words, the human agent, even as a necessary constituent of an eventcause, lacks the control required for the event-cause to count as an action or a doing.

To address this worry, event-causal theorists can draw on Randolph Clarke's distinction among three different types of control: 
[(1) bare actional control-where] action is causally brought about (in the right way) by, and hence motivated and guided by, certain of her reasons [; (2) rational control-where] at the time of her action, a capacity to reflect rationally on her alternatives and on the reasons favoring each, and to govern rationally her behavior on the basis of such reflection [; (3) direct agential control — where] the agent exercises a power-one that is distinct from the causal power of any events involving the agent - to causally influence which of the alternative actions left open by prior events will actually be performed. (Clarke 2009: 26-7)

The event-causal conception of the human agent, as a necessary constituent of an event-cause, possesses both bare actional control and rational control, but not direct agential control, which is exclusive to the agent-causal conception. While event-causal theorists argue that bare actional control and rational control are sufficient for an action or a doing, agent-causal theorists argue that direct agential control is necessary. But why suppose that direct agential control is necessary for an action or a doing when bare actional control and rational control seem to suffice? The answer, according to the agentcausal theorists, is that only uncaused agent-causes possess the direct agential control required to ground absolute free will which is in turn required to ground ultimate moral responsibility. Event-causal theorists can concede this point to the agent-causal theorists but they can challenge the need to accept the ultimacy condition for moral responsibility by appealing to Galen Strawson's argument for the impossibility of ultimate moral responsibility (Strawson 2009):

P1. To be ultimately responsible for what we do, we must be ultimately responsible for the way we are.

P2. We cannot be ultimately responsible for the way we are.

C1. Hence, we cannot be ultimately responsible for what we do.

P1 is supported by the reasonable assumption that what we do is at least in part determined by what we are, where what we are includes our character and personality, desires and beliefs, preferences and values, and sensitivity and responsiveness to external circumstances and situations. If this assumption is true, then absolute free will is 
ruled out along with ultimate moral responsibility.

P2 is supported as follows:

P3. To be ultimately responsible for the way we are, we have to be causa sui.

P4. We cannot be causa sui.

P2. Hence, we cannot be ultimately responsible for the way we are.

However, Strawson's argument allows for the possibility that we can be responsible (non-ultimately) for the way we are, and hence we can be responsible (non-ultimately) for what we do. That is, it is possible for event-causal theorists to reject the ultimacy condition without rejecting moral responsibility altogether. They can offer the following argument against postulating uncaused agent-causes: If the ultimacy condition is unnecessary for moral responsibility, then the absoluteness condition is unnecessary for free will. If the absoluteness condition is unnecessary for free will, then it is unnecessary to postulate uncaused agent-causes and direct agential control. If it is unnecessary to postulate uncaused agent-causes and direct agential control, then event-causes involving human agents, bare actional control, and rational control, are sufficient for free will. To complete the modus ponens: the ultimacy condition is unnecessary for moral responsibility, hence event-causes involving human agents are sufficient for free will. On the event-causal account, event-causes, bare actional control, and rational control are sufficient for (non-absolute) free will and (non-ultimate) moral responsibility, even if they are not sufficient for absolute free will and ultimate moral responsibility. But as Strawson's argument shows that ultimate moral responsibility and absolute free will are impossible, event-causal theorists can argue that (non-absolute) free will and (non-ultimate) moral responsibility are all we can have and all we will need.

\section{Conclusion}

It is not the aim of this paper to show that agent causation is impossible, for independent arguments for uncaused agent-causes and 
satisfactory solutions to the conceptual problems may be available. It is also not the aim of this paper to argue for a certain position in the free will debate, for the thesis of this paper can be shared by any compatibilist, incompatibilist, libertarian, or determinist position that favours event causation over agent causation. The aim of this paper is to show that agent causation is not prior to event causation, through objecting to Lowe's arguments for the claim that agent causation is prior to event causation, including the conceptual, linguistic, and ontological priority of agent causation over event causation, as well as the advantage agent causation has over event causation in grounding absolute free will and ultimate moral responsibility. To the extent that my objections against Lowe's arguments succeed, they cast doubts on O'Connor's and Clarke's claim that there are no good reasons to prioritise event causation over agent causation.

Soo Lam Wong Singapore University of Social Sciences Centre for University Core 463 Clementi Road, Singapore 599494 huang_shunan@yahoo.com.sg

\section{References}

Broad, C.D. 1952. "Determinism, indeterminism, and libertarianism”. In Ethics and the History of Philosophy. London: Routledge \& Kegan Paul.

Clarke, Randolph. 2009. "From agent causation and event causation in the production of free action”. In Free Will, ed. by Derk Pereboom. Indianapolis: Hackett.

Clarke, Randolph. 2003. Libertarian Accounts of Free Will. Oxford: Oxford University Press.

Ginet, Carl. 1997. "Freedom, responsibility, and agency." Journal of Ethics 1: 85-98.

Ginet, Carl. 1990. On Action. Cambridge: Cambridge University Press.

Kane, Robert. 1995. "Two kinds of incompatibilism”. In Agents, Causes, and Events, ed. by Timothy O'Connor. Oxford: Oxford University Press.

Kim, Jaegwon. 1975. "Events as property exemplifications”. In Action Theory, ed. by Myles Brand \& Douglas Walton. Dordrecht: Reidel Publishing Company.

Lowe, E.J. 2008. Personal Agency: The Metaphysics of Mind and Action. Oxford: Oxford University Press. 
Lowe, E.J. 2001. "Event causation and agent causation". Grazer Philosophische Studien 61(1): 1-20.

Mackie, John L. 1993. "Causes and conditions". In Causation, ed. by Ernest Sosa \& Michael Tooley. Oxford: Oxford University Press.

O’Connor, Timothy. 2009. “Agent-causal power”. In Free Will, ed. by Derk Pereboom. Indianapolis: Hackett.

O'Connor, Timothy. 2000. Persons and Causes. Oxford: Oxford University Press.

O’Connor, Timothy. 1995. "Agent causation”. In Agents, Causes, and Events, edited by Timothy O'Connor. Oxford: Oxford University Press.

Shoemaker, Sydney. 1984. "Causality and properties". In Identity, Cause and Mind. Cambridge: Cambridge University Press.

Strawson, Galen. 2009. "The impossibility of ultimate moral responsibility". In Free Will, ed. by Derk Pereboom. Indianapolis: Hackett.

Taylor, Richard. 1974. Metaphysics ( $2^{\text {nd }}$ Edition). Englewood Cliffs: Prentice Hall.

Taylor, Richard. 1966. Action and Purpose. Englewood Cliffs: Prentice Hall. 